\title{
RECONSTRUCCIÓN DE UNA HUELLA OLVIDADA LOS ÁLBUMES DE ISMAEL ERRIEST
}

\author{
THE RECONSTRUCTION OF A FORGOTTEN TRACE \\ ISMAEL ERRIEST'S ALBUMS
}

\author{
Arturo Aristizábal | Ic.aristizabal.arturo@gmail.com \\ Bárbara Martín Pozzi | neferbar@hotmail.com \\ Graciela Piccolo | cgrapiccolo@gmail.com \\ Facultad de Bellas Artes. Universidad Nacional de La Plata. Argentina
}

Recibido: 9/4/2018 | Aceptado: 23/7/2018

\section{RESUMEN}

En el presente artículo se analizan cinco biblioratos que fueran donados por una de las hijas del Dr. Ismael Erriest y que hoy integran el acervo del Archivo Histórico de la provincia de Buenos Aires. Este material está conformado por fotografías, recortes periodísticos, afiches y otros elementos que dan cuenta de la vida política de uno de los miembros más distinguidos del Partido Conservador de la ciudad de La Plata y de la localidad de Lobos, entre los años 1910 y 1954: el Dr. Erriest. Gracias al archivo, las huellas se actualizan en un gesto de escritura y de lectura, que nos permite colegir el deseo, por parte del autor, de que las mismas pervivan.

\section{PALABRAS CLAVE}

Archivo; Ismael Erriest; imágenes; materialidad

\section{ABSTRACT}

In the present article, five libraries are analyzed that were donated by one of the daughters of Dr. Ismael Erriest and that today integrate the archive of the Historical Archive of the province of Buenos Aires.

This material is made up of photographs, newspaper clippings, posters and other elements that give an account of the political life of one of the most important members of the Conservative Party of La Plata and Lobos between 1910 and 1954, Dr. Erriest. Thanks to the archive, the prints are updated in a gesture of writing and reading, allowing us to collect the desire to survive them by their author.

\section{KEYWORDS}

Archive; Ismael Erriest; images; materiality 
Acercarnos al Archivo Histórico de la provincia de Buenos Aires en el marco de las prácticas de archivo de la cátedra Teoría de la Historia, nos permitió encontrar una gran cantidad de documentos judiciales e institucionales, además de encuadernaciones de épocas pasadas en variados formatos, con tonalidades marrones y amarillas que dan cuenta del paso del tiempo.

Caminar en el archivo es mezclarse con diferentes tiempos y personas, entre paredes tapizadas de estanterías, donde conviven delgados catálogos llenos de fotografías con libros robustos o pequeños. En ese deambular vino a nuestro encuentro una elaborada caligrafía del siglo XVIII materializada en la firma del Virrey Cisneros y con el relato preciso del 18 de mayo del año 1781, sobre la ejecución de Túpac Amaru en la Plaza de Armas de Cuzco.

El espacio es visitado por un público de edades y de procedencias disímiles: estudiantes de todos los niveles educativos, profesionales de distintas áreas y personal de archivos municipales, que llegan al lugar en busca de información y de actualización de la práctica archivística, entre otros temas. El visitante ingresa expectante al hall central donde es recibido por quienes trabajan en el repositorio y, así como a nosotros, le relatan la historia, los contenidos y los objetivos del mismo.

Llegar al archivo fue transitar esa experiencia personal, tal como la expresa María del Carmen Jaramillo (2010): «Los archivos permiten comprender la pluralidad de las dimensiones del tiempo y pueden ser el pasadizo a través del cual se genera un diálogo entre voces y contextos de diferentes momentos y lugares» (p. 4). De ese modo, comenzamos a ocupar un espacio en el repositorio y fuimos armando un rompecabezas sin modelo que nos permitió realizar una lectura del pasado.

En esta práctica investigativa tomamos como objeto de estudio los álbumes personales del Dr. Ismael Erriest, que guarda y conserva el Archivo Histórico Provincial. Erriest, oriundo de Lobos, realizó sus estudios secundarios y universitarios en la ciudad de La Plata, graduándose como abogado. Se desempeñó como funcionario en diversas áreas del Poder Ejecutivo y Legislativo provincial entre los años 1930 y 1954.

En nuestro primer acercamiento, encontramos que estos álbumes contienen diferentes tipos de fotografías, gráficos y artículos, seleccionados y dispuestos a partir del valor intrínseco que les otorgó su autor. Los mismos fueron donados al archivo por su hija, Graciana Erriest, en el año 2010 y su acercamiento a la institución se produjo a través de un integrante de la Asociación Amigos del Archivo.

Al pasar las páginas de los álbumes, se puede reconocer un relato testimonial por parte del Dr. Erriest, aunque lo más interesante es la variedad de materiales y el cuidado y la prolijidad con que cada elemento se dispone dentro de los libros. Esto nos remite a los aportes de Gabriela Siracusano (2008) quien sostiene que «una imagen se torna eficaz cuando su propia materialidad no solo acompaña 
sino también construye sentido» (p. 10). Así, es posible observar como Erriest construye un relato de su vida, desde temprana edad, evidenciado por su boletín de calificaciones del año 1910 que corresponde a la educación primaria, como referencia y testimonio de sus primeros años [Figura 1].

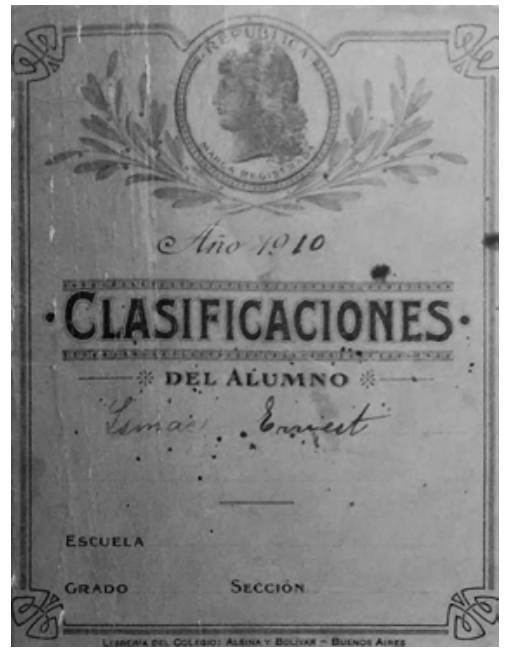

Figura 1. Libreta de clasificaciones del alumno (1910). Álbum de Ismael Erriest. Archivo Histórico de la provincia de Buenos Aires

De igual modo, exhibe el ascenso que tuvo su carrera política y la llegada al poder del Partido Conservador al que perteneció [Figura 2], a través de la adhesión de panfletos de las campañas en las que participó. Con esto, no solo está haciendo alusión a una época determinada de su vida, sino que además pone un fragmento de aquel momento frente al espectador-lector.

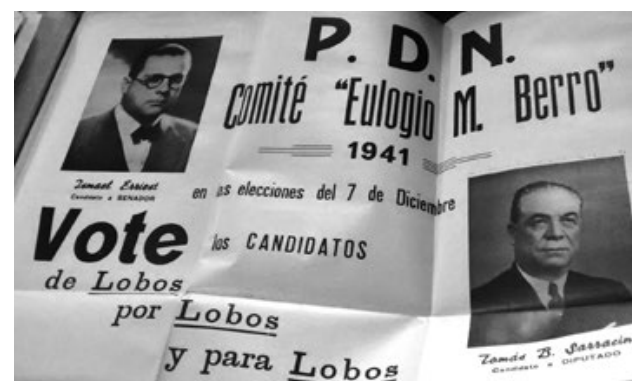

Figura 2. Afiche de la campaña electoral del Partido Demócrata Nacional (1941). Álbum de Ismael Erriest. Archivo Histórico de la provincia de Buenos Aires 
Las cualidades de los cinco álbumes en cuanto al tamaño, la calidad de las tapas, las hojas que los conforman y el tipo de encuadernación idéntico, coinciden con la dedicación y el esmero que el autor brindó a la realización y a la organización de su propio archivo. Esto se puede ver en la prolijidad de los recuadros confeccionados para cada artículo y fotografía [Figura 3] -acompañados de la respectiva fecha y título-, lo cual nos permite conjeturar la intención de que los mismos pervivan.

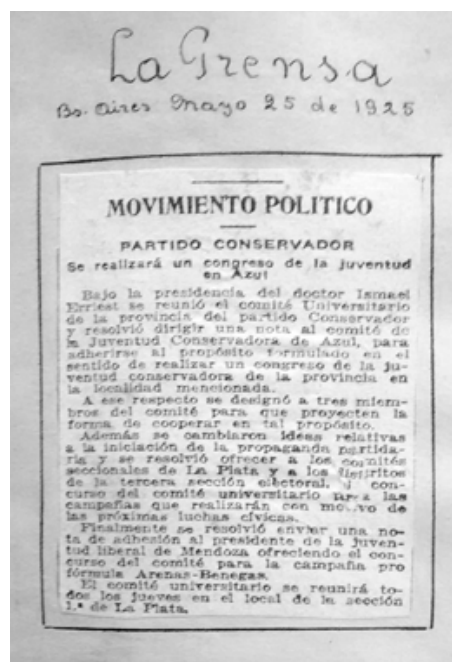

Figura 3. La prensa (1925). Recorte de un artículo periodístico. Álbum de Ismael Erriest. Archivo Histórico de la provincia de Buenos Aires

De este modo, podemos suponer que la pretensión que persiguió Erriest fue dar una prueba acabada de la linealidad de la historia y conseguir que su archivo fuese un fragmento de su visión y de su concepción de la política argentina entre 1930 y 1950.

Por otra parte, el archivo como documento se actualiza en un gesto de escritura y de lectura; en este marco, pudimos comprobar que la institución provincial no contaba con una ficha técnica ni con una catalogación de los álbumes consultados que permitiera su ubicación física, conceptual o temática en el acervo patrimonial. Si bien esto nos generó, en un primer momento, cierta incertidumbre, al acercarnos a los documentos ofició de entrada a nuestra labor de investigación para asumir un rol reconstructivo de la huella. 


\section{ENTRETEJER FRAGMENTOS DE UNA VIDA}

En contacto con los cinco álbumes pudimos trazar la ruta y darle un orden al relato construido por Erriest. Estos documentos establecen implícitamente una continuidad que se manifiesta entre el inicio y el final de cada uno, lo que permite comprenderlos como capítulos que conforman el discurso de nuestra reconstrucción. En consecuencia, brindamos un título a cada volumen que expresa metafóricamente el contenido de los mismos.

El álbum que designamos con el nombre de Génesis de una vido militante comienza consignando el período de marzo de 1910 y contiene, como epígrafe, un boletín de calificaciones que da cuenta del tránsito de Ismael Erriest por la escuela primaria. Continúa con recortes de su internado en el Colegio Nacional de La Plata, su participación en la agrupación Universidad de La Plata Internado (ULPI), su citación al servicio militar obligatorio y sus inicios como militante político del Partido Conservador. Este álbum finaliza con recortes periodísticos del año 1939.

«La política, su pasión» es un capítulo compuesto por dos álbumes, que nos permite adentrarnos en lo que fue, significó y estuvo centrada su vida pública. Recorre un itinerario que abarca desde los años 1939 a 1943, el primer álbum, y desde 1943 a 1950, el segundo. Se trata de períodos en los que desempeñó distintos cargos públicos y fue electo senador provincial por la tercera sección electoral. Estos dos volúmenes hacen hincapié en los proyectos vinculados a Lobos, su ciudad natal, tales como la inauguración del pabellón de tuberculosos y la creación del centro de turismo, entre otros. Contienen además recortes periodísticos que refieren a hechos puntuales de su vida personal.

«Imágenes de una época» es la denominación de los dos álbumes restantes, conformados exclusivamente por fotografías tomadas por Erriest que constituyen una memoria gráfica de la sociedad y la cultura. A través de ella, el autor da cuenta de su manera de participar, de pensar, de sentir y de concebir la realidad de su época, creando un conjunto de relaciones visuales por medio de la fotografía [Figura 4]. Esto nos permite observar una antropología de lo imaginario, una hermenéutica de lo simbólico (Marin, 1992). El encuadre, el plano y la composición de las fotografías conllevan la intencionalidad de Erriest de atesorar costumbres y características propias de la clase social a la que perteneció. 


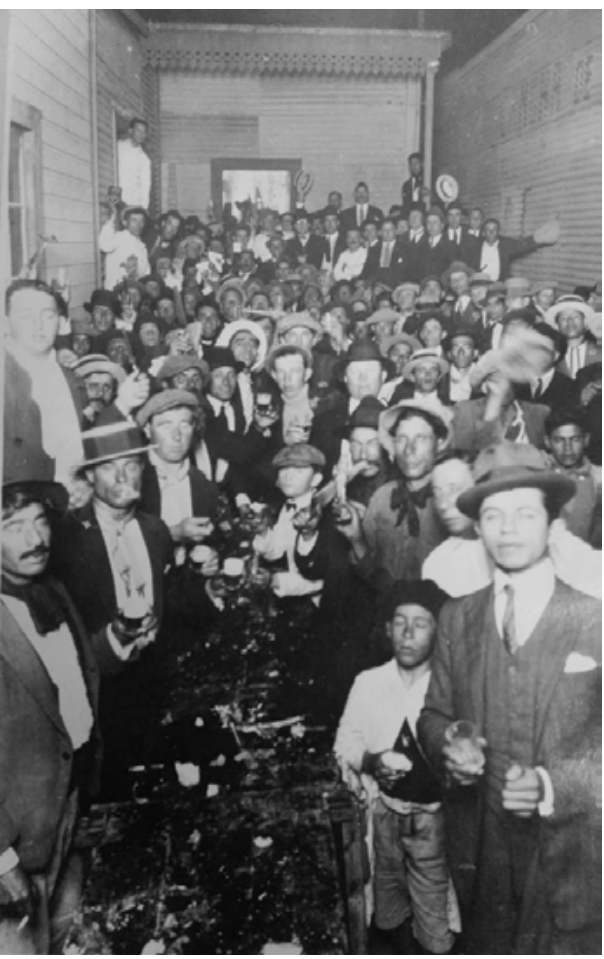

Figura 4. Berisso (s/f). Álbum de Ismael Erriest. Archivo Histórico de la provincia de Buenos Aires

\section{REFERENCIAS}

Archivo particular de Ismael Erriest (s/f). Álbumes N. ${ }^{\circ} 1, N{ }^{\circ} 2$ y N. ${ }^{\circ}$ : Fotos de su actuación pública y privada. La Plata, Argentina: Archivo histórico de la provincia de Buenos Aires Ricardo Levene.

Archivo particular de Ismael Erriest (s/f). Álbumes N. ${ }^{\circ} 4$ y N. ${ }^{\circ 5}$ : Recortes de arículos periodísticos de su vida pública. La Plata, Argentina: Archivo histórico de la provincia de Buenos Aires Ricardo Levene.

Jaramillo, M. C. (2010). Archivos y política/políticas de archivo. Errato. Revisto de Artes visuales, (1), 14-20. Recuperado de http://revistaerrata.com/ediciones/ errata-1-arte-y-archivos/archivos-y-politica-Politicas-de-archivo/ 
Marin, L. (1992). El cuerpo de poder y la encarnación en Port Royal y Pascal o de la 'figurabilidad' del absoluto político. En M. Feher, R. Naddaff, y N. Tazi, (eds.), Fragmentos para una historia del cuerpo humano. T. III. (pp. 421-447). Madrid, España: Taurus.

Ricoeur, P. (2004). Lo memorio, la historio y el olvido. Buenos Aires, Argentina: Fondo de Cultura Económica.

Siracusano, G. (2008). Los entrañas del arte. Un relato material (S. XVII-XIX). Buenos aires, Argentina: Fundación Osde. 